\title{
Meningkatkan Hasil Belajar Ekonomi Siswa dengan Model Pembelajaran Kooperatif Tipe Mind Mapping
}

\author{
Gabby Farada Mayura Arifin*1, Luh Indrayani ${ }^{2}$ \\ 1,2Program Studi Pendidikan Ekonomi \\ Universitas Pendidikan Ganesha \\ Singaraja, Indonesia
}

\section{e-mail: gebyfarada@gmail.com ${ }^{* 1}$, luhindrayani25@gmail.com²}

\section{Riwayat Artikel Tanggal diajukan: 20 Desember 2020 \\ Tanggal diterima : 15 April 2021 \\ Tanggal dipublikasikan: 25 Juni 2021}

Pengutipan:

Arifin, G. F.

Meitriana, M. A. \& Indrayani, L. (2021). Pengaruh Model

Pembelajaran Kooperatif Tipe Mind Mapping Terhadap Hasil Belajar Ekonomi Pada Siswa Kelas $X$ di

SMA Negeri 3

Singaraja Tahun Ajaran

2020/2021. Jurnal

Pendidikan

Ekonomi

Undiksha, 13(1),

1-8

http://dx.doi.org/1

$\underline{0.23887 / \text { jipe.v13 }}$

1.30540

\begin{abstract}
Abstrak
Pemetaan pikiran, atau istilahnya Mind Mapping dan Problem Based Learning, keduanya peneliti aplikasikan sebagai model di kelas eksperimen dan kelas kontrol pada pembelajaran riset ini. Penelitian ini tertuju ke arah mencari adanya perbedaan positif serta signifikan hasil belajar pelajaran ekonomi antara keduanya atau tidak. Pada kelas eksperimen yang memakai Mind Mapping sebagai model dalam pembelajaran, peneliti memakai X IPS 1 pada riset ini. Sedangkan, pada kelas kontrol yang memakai Problem Based Learning sebagai model dalam pembelajaran, peneliti memakai X IPS 3 pada riset ini. Desain quasi eksperimen, atau metode yang didesain tanpa me-random kelas eksperimen dan kelas kontrol pada riset dan hanya diberi post-test setelah diberikan perlakuan, atau dikenal dengan istilah Non-Equivalent Post-Test Only Control Group Design yang peneliti gunakan sebagai metode riset ini. Semua siswa kelas $X$ berjumlah 90 orang yang masing-masing terbagi 3 kelas menjadi populasi dalam riset ini. Teknik sampling acak yang sederhana, dikenal dengan istilah Simple Random Sampling juga peneliti pilih di dalam riset ini, dari 3 kelas populasi, peneliti memilih X IPS 1 dan kelas X IPS 3 menjadi sampel. Post-test dipilih sebagai metode pengumpulan data, setelah data post-test didapat kemudian data tersebut akan dianalisis menggunakan teknik dari uji $\mathrm{t}$ (uji parsial) yang dalam bahasa inggrisnya dikenal dengan istilah uji independent sample t-test. Peneliti menerima hasil dari program statistik komputer SPSS 24.0 for Windows dengan hasil Sig. (2-tailed) $=0,000$. Agar dapat mendukung riset ini, nilai signifikansi harus $<0,005$, dan itu artinya hasil nilai Signifikansi pada riset ini yakni 0,000< 0,005 . Hasil tersebut peneliti gunakan sebagai bukti diterimanya hipotesis penelitian pada riset ini yakni adanya perbedaan positif serta signifikan hasil belajar pelajaran ekonomi antara keduanya, yakni yang diaplikasikan Mind Mapping dan Problem Based Learning sebagai model dalam pembelajaran pada riset di SMA Negeri 3 Singaraja tahun pelajaran 2020/2021 yang di khususkan pada kelas $X$.
\end{abstract}

Kata Kunci: model pembelajaran; mind mapping; hasil belajar.

Abstract
Mind mapping, or the term Mind Mapping and Problem Based Learning, both
researchers apply as a model in the examiner class and the monitoring class in
this research learning. This research is aimed at notifying whether or not a
significant difference can be found between the two or not in economic lessons
that are focused on student learning outcomes. In the class of examiners who
use Mind Mapping as a model in learning, the researcher uses X IPS 1 in this
research. Meanwhile, in the review class that used Problem Based Learning as
a model in learning, researchers used X IPS 3 in this research. Quasi-
experimental design, or a method that is designed without randomizing the
examiner class and the monitoring class in the research and is only given a post-


test after being given treatment, otherwise known as the Non-Equivalent PostTest Only Control Group Design which the researcher uses as this research method. . All students in class $X$ totaled 90 people, each of whom was divided into 3 classes into the population in this research. Sampling technique, known as Simple random samplingSimple Random Sampling, is also the researcher's choice of in this research, from 3 population classes, the researcher chooses $X$ IPS 1 and class X IPS 3 to be the sample. The post-test was chosen as the data collection method, after the post-test data was obtained then the data would be analyzed using a technique from the t test (partial test) which in English is known as the independent sample t-test. Researchers received the results from the computer statistical program SPSS 24.0 for Windows with the results of Sig. (2tailed) $=0.000$. In order to support this research, the significance value must be $<0.005$, and that means the result of the Significance value in this research is $0.000<0.005$. The results of these researchers used as evidence of acceptance of the research hypothesis in this research, namely that there was a significant difference between student learning outcomes in economic subjects using thetype of cooperative learning model and Mind Mapping student learning outcomes in economic subjects usinglearning models Problem Based Learning in class. X SMA Negeri 3 Singaraja, 2020/2021 academic year.

Keywords : learning models; mind mapping; learning outcomes.

\section{PENDAHULUAN}

Pembelajaran ekonomi yakni pembelajaran yang sifatnya dinamis, begitu dekat dengan kehidupan sehari-hari siswa. Kebutuhan, pilihan, kelangkaan, prioritas dan konsep lainnya yang berkaitan dengan konsep ekonomi banyak dijumpai dalam kegiatan ekonomi dan diajarkan dalam disiplin ilmu ekonomi, dimana siswa memperolehnya di pendidikan formal (Prahara dkk, 2016). Setiap pembelajaran di sekolah termasuk pembelajaran ekonomi tentu akan melewati suatu proses pembelajaran, proses ini biasanya menjadikan siswa sebagai input, pembelajaran sebagai komponen proses, dan hasil akhir atau output menghasilkan hasil belajar siswa. Hasil tersebut ialah indikator dalam pembelajaran yang menunjukkan kemampuan dan pemahaman siswa dalam mencapai tujuan belajar ekonomi.

Hasil belajar ialah indikator yang menujukkan kemampuan dan pemahaman siswa dalam belajar, yang diukur dengan menggunakan tes sebagai alat ukur yang dapat menunjukkan kemampuan aktual siswa (Hermaswari dkk, 2019). Pada setiap pembelajaran baik guru maupun peserta didiknya pasti berharap akan memperoleh hasil belajar yang efektif, sebagai penentu keberhasilan guru dalam mengajar. Jadi keberhasilan belajar akan terjadi jika hasil belajar memberikan efek bagi siswa berupa perkembangan yang lebih baik dari sebelumnya (Fauziah, 2017). Selain itu, waktu serta tenaga yang dikeluarkan juga akan lebih efisien sehingga tidak perlu lagi melakukan perbaikan dalam pembelajaran.

Tidak bisa lepas dari mampunya seorang guru dalam keahliannya mengembangkan model pembelajaran, keterampilan pememilihan model pembelajaran oleh seorang guru yang tepat dan sesuai juga tak kalah pentingnya dalam keberhasilan proses pembelajaran, maknanya pemilihan model yang tepat berguna untuk meningkatkan intensitas partisipasi dalam proses pembelajaran secara efektif untuk siswa. Pengembangan model pembelajaran tersebut, yang tepat dan yang sesuai harus dapat diciptakan, terutama agar kondisi pembelajaran memperoleh presentase aktivitas yang lebih besar karena perasaan gembira dalam mengikuti proses pembelajaran oleh para siswa, sehingga siswa berhasil dalam memperoleh hasil dan prestasi belajar yang terbaik (Aunurrahman, 2012). Agar efektifnya pengembangkan model pembelajaran, setiap guru harus memiliki kecukupan pemahaman tentang konsep dan cara penerapan model pembelajaran (Aunurrahman, 2012). Tanpa memahami berbagai kondisi tersebut, model yang dikembangkan oleh guru seringkali tidak 
dapat meningkatkan partisipasi belajar siswa secara maksimal, sehingga pada akhirnya tidak dapat mengasih kontribusi yang berarti kepada siswa terhadap realisasi hasil belajar. oleh karenanya, model pembelajaran yang baik jika tepat dipilih oleh guru berdasarkan kebutuhan pembelajaran yang sesuai dan dipakai dalam proses pembelajaran tersebut tentunya akan mempengaruhi hasil belajar di setiap pembelajaran. Model pembelajaran merupakan kerangka konseptual yang memuat tata cara sistem penyelenggaraan pembelajaran yang prosesnya diperuntukkan dalam upaya mencapai tujuan pembelajaran (Tayeb, 2017).

Terdapat banyak pilihan model yang dapat guru pilih dalam pembelajaran, model-model tersebut memiliki keunggulan yang disertai dengan kelemahannya masing-masing pada saat diaplikasikan pada pembelajaran. Dasar pertimbangan pemilihan model pembelajaran yaitu, pertama pertimbangan tujuan yang ingin dicapai, pertimbangan kedua ialah faktorfaktor yang terkait dengan materi pembelajaran dan bahan ajar, pertimbangan ketiga yakni dari segi perspektif peserta didik, dan pertimbangan keempat yaitu pertimbangan nonteknis lainnya (Nurdyansyah, \& Fahyuni, 2016). Dasar-dasar pertimbangan pemilihan model pembelajaran tersebut menuntut guru harus membuat kegiatan pembelajaran, kegiatan tersebut ialah sanggup mengubah pengetahuan siswa yang sebelumya tidak sesuai seperti konsep materi pembelajaran akan menjadi sesuai, dan jika pengetahuan awal yang dimiliki siswa telah sesuai dengan konsep materi pembelajaran maka seorang guru juga harus mampu untuk menyempurnakan konsep siswa dari yang sebelumnya. Oleh karena itu, pentingnya model pembelajaran yang sanggup mengubah dan menyempurnakan pengetahuan awal yang telah dimiliki siswa sesuai dengan konsepnya dan peneliti memilih Mind Mapping sebagai model yang akan digunakan dalam pembelajaran pada riset ini.

Mind Mapping adalah model yang dirancang agar siswa dapat dengan mudah menyimpan informasi yang diterima dalam proses pembelajaran, lalu menyusunnya ke dalam inti-inti yang penting berbentuk peta, simbol dan grafik agar siswa tidak sukar dalam belajar dan juga lekas sekali dalam mengingat apa yang telah dipelajarinya. dengan teknik grafis seperti itu, siswa merasa tidak sukar lagi untuk mengingat pelajaran yang telah mereka pelajari sebelumnya. Melalui model pembelajaran Mind Map, siswa tidak perlu lagi mencatat tulisan yang didiktekan oleh guru atau yang dituliskan di papan tulis secara keseluruhan karena siswa dapat dengan mudah mengetahui inti dan konsep yang siswa pelajari kemudian membuat peta pikirannya sesuai dengan kreativitas masing-masing siswa (Syam \& Ramlah, 2015). Oleh karena itu, Mind Mapping mengajari siswa cara meringkas dan menemukan esensi materi pembelajaran secara terstruktur. Mind Mapping atau istilah dalam bahasa indonesianya adalah peta pikiran sangat berguna untuk memahami materi khususnya materi yang akan dicerna oleh otak siswa semasa proses pembelajaran berlangsung.

Peninjauan yang diadakan pada pembelajaran ekonomi, yang dilaksanakan di SMA Negeri 3 Singaraja, tepatnya pada kelas $\mathrm{X}$. Peninjauan tersebut ditemukan guru selalu memeriksa catatan para siswanya dan memberikan nilai, pengambilan nilai tersebut bertujuan mendorong siswa agar mau memperhatikan guru dalam penyampaian materi. Selain itu, guru ingin memperkaya materi dan bahan belajar untuk dipelajari siswanya sebelum ulangan berlangsung dengan cara memberikan tambahan bahan belajar untuk dicatat oleh siswa, apalagi dengan sumber belajar yang disediakan sekolah hanya satu buku LKS, guru ingin memudahkan siswanya dalam belajar sehingga harapannya para siswa mendapat nilai yang lebih baik pada ulangan tersebut. Namun pada proses pembelajaran ekonomi tersebut diperoleh keterangan bahwa beberapa siswa ada yang tidak mau mencatat catatan dari guru, kebanyakan siswa hanya mendengar pelajaran tersebut. Jika siswa ditanya terkait penyebab siswa yang tidak mencatat dikarenakan materi yang didikte 
terlalu cepat sehingga siswa tidak sempat untuk mencatatnya. Guru lebih sering mendikte materi pelajaran yang bersumber dari buku atau sumber lain yang materinya cukup banyak. Siswa pun tidak mengerti dengan inti dari materi yang diajarkan. Pembelajaran cenderung lebih banyak berlalu dengan kegiatan mendikte materi yang disediakan oleh guru, sehingga siswa merasa malas untuk mencatatnya. Model pembelajaran yang digunakan pada pembelajaran ekonomi, yang dilaksanakan di SMA Negeri 3 Singaraja, tepatnya pada kelas $\mathrm{X}$ ini masih menggunakan (teacher centered) dalam sistem belajarnya atau pembelajaran yang berpusat pada guru membuat siswa merasa bosan pada saat pembelajaran ekonomi berlangsung. Hal tersebut menujukkan ketidaksesuaian antara harapan guru dengan kenyataan yang terjadi pada para siswanya. Hal tersebut terbukti dari hasil belajar pada pembelajaran ekonomi, yang dilaksanakan di SMA Negeri 3 Singaraja, tepatnya pada kelas $\mathrm{X}$, dari perolehan nilai tes bab satu masih banyak siswa dengan standar integritas minimal (KKM) ke bawah.

Dari permasalahan tersebut, untuk meningkat hasil belajar siswa pada pembelajaran ekonomi, yang dilaksanakan di SMA Negeri 3 Singaraja, tepatnya pada kelas $\mathrm{X}$ dapat menggunakan kooperatif tipe Mind Mapping sebagai model dalam pembelajaran pada riset ini, peneliti berharap dengan model tersebut dapat menaikkan hasil belajar yang akan diperoleh siswa.

\section{METODE}

Mind Mapping dan Problem Based Learning, keduanya peneliti aplikasikan sebagai model di kelas eksperimen dan kelas kontrol pada pembelajaran riset ini. Penelitian ini tertuju ke arah mencari adanya perbedaan positif serta signifikan hasil belajar pelajaran ekonomi antara keduanya atau tidak. Pada kelas eksperimen yang memakai Mind Mapping sebagai model dalam pembelajaran, peneliti memakai X IPS 1 pada riset ini. Sedangkan, pada kelas kontrol yang memakai Problem Based Learning sebagai model dalam pembelajaran, peneliti memakai X IPS 3 pada riset ini. Riset ini berjenis quasi eksperimen yang didesain tanpa me-random kelompok-kelompok perlakuan yang kedua kelas tersebut hanya diberi post-test setelah diberikan perlakuan, atau dikenal dengan istilah Non-Equivalent Post-Test Only Control Group Design. Riset ini lokasinya di Jl. Pulau Natuna Penarukan, Kota Singaraja, Kecamatan Buleleng, Bali, tepatnya dilaksanakan di SMA Negeri 3 Singaraja.

Siswa berjumlah 90 orang yang masing-masing terbagi 3 kelas menjadi populasi dalam riset ini, tepatnya siswa seluruhnya di kelas $X$. Teknik sampling acak yang sederhana, dikenal dengan istilah Simple Random Sampling juga peneliti pilih di dalam riset ini, dari 3 kelas populasi hanya 2 kelas yang dipilih, dan peneliti memilih X IPS 1 dan X IPS 3. Posttest dipilih sebagai metode pengumpulan data. Ada total 20 pertanyaan dengan perolehan 1 untuk yang benar dan 0 untuk yang salah sebagi skor.

Langkah-langkah yang mengarahkan peneliti kepada tindakan-tindakan agar dapat menjalankan penelitian dengan baik dan benar ditentukan oleh prosedur penelitian yaitu orientasi dan observasi awal untuk menentukan kelas yang digunakan untuk melakukan penelitian dengan melihat nilai akhir siswa, yang sudah dikonsultasikan dengan guru mata pelajaran ekonomi. Kemudian, peneliti menentukan bahan ajar yang digunakan untuk penelitian, menyusun perangkat pembelajaran seperti RPP dan LKS satu kompetensi dasar untuk kelas eksperimen yang memakai Mind Mapping sebagai model dalam pembelajaran, peneliti memakai $X$ IPS 1 pada riset ini. Sedangkan, pada kelas kontrol yang memakai Problem Based Learning sebagai model dalam pembelajaran, peneliti memakai X IPS 3 pada riset ini yang dilaksanakan sebanyak tiga kali petemuan, dua kali pertemuan memberikan treatment selanjutnya satu kali memberikan post test untuk kedua kelas yang akan diberikan treatment tersebut yaitu kelas eksperimen, yang lebih dahulu soal post test tersebut dikonsultasikan dengan guru mata pelajaan ekonomi kelas $\mathrm{X}$ kemudian dikonsultasikan dengan dosen pembimbing. Setelah itu, merevisi perangkat pembelajaran seperti 
RPP, media pembelajaran dan LKS untuk kelas eksperimen dan kelas kontrol yang telah terbimbing oleh dosen pembimbing dan guru mata pelajaran ekonomi kelas $X$. Kemudian, menyusun instrumen penelitian yang disusul dengan konsultasi ke dosen pembimbing dan guru mata pelajaran ekonomi kelas $X$. Setelah itu, peneliti memberikan perlakuan dengan mengaplikasikan pada kelas eksperimen yang memakai Mind Mapping sebagai model dalam pembelajaran, peneliti memakai $X$ IPS 1 pada riset ini. Sedangkan, pada kelas kontrol yang memakai Problem Based Learning sebagai model dalam pembelajaran, peneliti memakai X IPS 3 pada riset ini dengan daring online. Tahap terakhir, peneliti memberikan post-test yang sama kepada kelas eksperimen dan kelas kontrol atau lebih dikenal dengan kelas eksperimen dan kontrol, kemudian analisis data penelitian baru bisa dikerjakan untuk menguji hipotesis penelitian.

Uji prasyarat lebih dahulu dilakukan sebelum menganalisis data, yaitu pertama diuji dulu normalitasnya. Agar dapat mendukung riset ini atau agar datanya normal, nilai signifikansi harus $<0,005$. setelah itu, diuji homogenitasnya. Agar dapat mendukung riset ini, sama seperti uji normalitas, data yang homogen nilai signifikansi harus $<0,005$. Setelah kedua uji tersebut telah lolos, uji hipotesis dapat terlaksana dalam riset ini. Peneliti menerima hasil dari program statistik komputer SPSS 24.0 for Windows mengunakan uji t (uji parsial), atau istilah bahasa inggrisnya uji independent sample t-test dipilih dalam teknik analisis data.

\section{HASIL DAN PEMBAHASAN}

Hasil Penelitian

Peneliti menerima hasil dari program statistik komputer SPSS 24.0 for Windows. Hasil yang ditemukan oleh peneliti, terdapat adanya perbedaan positif serta signifikan hasil belajar pelajaran ekonomi antara kedua kelas riset. Pada kelas eksperimen yang memakai Mind Mapping sebagai model dalam pembelajaran, peneliti memakai X IPS 1 pada riset ini. Sedangkan, pada kelas kontrol yang memakai Problem Based Learning sebagai model dalam pembelajaran, peneliti memakai X IPS 3 pada riset ini. Tabel 1 dibawah ini disajikan untuk memperlihatkan ringkasan dari uji $t$ (uji parsial) yang dalam bahasa inggrisnya disebut dengan independent sample t-test.

Tabel 1. Hasil Uji Independent Sample t-Test

Hasil Belajar Ekonomi di Kelas X SMA Negeri 3 Singaraja Independent Sample t-Test

baris yang tersaji, $0,000<0,005$ atau nilai

\begin{tabular}{|c|c|c|c|c|c|c|c|c|c|c|}
\hline & & $F$ & Sig. & $\mathrm{T}$ & $\mathrm{df}$ & $\begin{array}{l}\text { Sig. } \\
(2- \\
\text { taile } \\
\text { d) }\end{array}$ & $\begin{array}{c}\text { Mean } \\
\text { Differe } \\
\text { nce }\end{array}$ & $\begin{array}{l}\text { Std. } \\
\text { Error } \\
\text { Differe }\end{array}$ & $\begin{array}{r}95 \% \text { Co } \\
\text { Interva } \\
\text { Diffe }\end{array}$ & $\begin{array}{l}\text { fidence } \\
\text { of the } \\
\text { nce }\end{array}$ \\
\hline & & & & & & & & & Lower & Upper \\
\hline Hasil & $\begin{array}{l}\text { Equal } \\
\text { variances } \\
\text { assumed }\end{array}$ & ,000 & 1,000 & 6,067 & 58 & ,000 & 11,000 & 1,813 & 7,371 & 14,629 \\
\hline $\begin{array}{l}\text { Belajar } \\
\text { Siswa }\end{array}$ & $\begin{array}{l}\text { Equal } \\
\text { variances } \\
\text { not } \\
\text { assumed }\end{array}$ & & & 6,067 & 58,000 & ,000 & 11,000 & 1,813 & 7,371 & 14,629 \\
\hline
\end{tabular}

Agar dapat mendukung riset ini, nilai signifikansi harus $<0,005$. Berdasarkan ringkasan Independent Sample t-Test yang telah tersaji pada Tabel 1, pada kolom Sig. (2-tailed) terdapat nilai 0,000 pada kedua signifikansi $<0,005$ mengindikasikan $\mathrm{H}_{0}$ dapat diterima. Selanjutnya, Tabel 2 dibawah ini disajikan untuk dapat membandingkan rata-rata hasil belajar pada kedua kelas variabel tersebut. 
Tabel 2. Perbandingan Hasil Belajar Ekonomi di Kelas X SMA Negeri 3 Singaraja Group Statistics

\begin{tabular}{llcccc}
\hline Kelas & N & Mean & Std. Deviation & $\begin{array}{c}\text { Std. Error } \\
\text { Mean }\end{array}$ \\
\cline { 2 - 5 } Hasil Belajar Siswa & $\begin{array}{l}\text { Post-Test Eksperimen } \\
\text { (Mind Mapping) }\end{array}$ & 30 & 83,00 & 7,022 & 1,282 \\
$\begin{array}{l}\text { Post-Test Kontrol } \\
\text { (Problem Based } \\
\text { Learning) }\end{array}$ & 30 & 72,00 & 7,022 & 1,282 \\
\hline
\end{tabular}

Berdasarkan ringkasan yang telah tersaji pada Tabel 2, hasil 83,00 menujukkan nilai dari kolom Mean pada baris hasil belajar Post-Test Eksperimen (Mind Mapping), sedangkan hasil 72,00 menujukkan nilai dari kolom Mean pada baris hasil belajar Post-Test Kontrol (Problem Based Learning).

\section{Pembahasan}

Pembahasan di atas menjadi dasar peneliti untuk menunjukkan bahwa, adanya perbedaan positif serta signifikan hasil belajar pelajaran ekonomi antara kedua kelas riset. Pada kelas eksperimen yang memakai Mind Mapping sebagai model dalam pembelajaran, peneliti memakai $X$ IPS 1 pada riset ini. Sedangkan, pada kelas kontrol yang memakai Problem Based Learning sebagai model dalam pembelajaran, peneliti memakai X IPS 3 pada riset ini di kelas X SMA Negeri 3 Singaraja tahun pelajaran 2020/2021 yang dapat dilihat dari uji statistik penelitian.

Penerapan Mind Mapping sebagai model pembelajaran pada saat peneliti melakukan penelitian terlihat siswa lebih aktif bertanya maupun lebih aktif menjawab pada saat diskusi antar kelas dan keaktifan tersebut bersifat merata bagi siswa yang pintar atau yang belum pintar

sehingga tidak terlihat adanya kesenjangan. Sedangkan, pada saat pengaplikasian Problem Based Learning sebagai model dalam pembelajaran terdapat beberapa siswa yang aktif dan semakin terbuka wawasannya, mereka menganggap bahwa pembelajaran yang berbasis masalah ini lebih menantang dan menyenangkan, namun hal tersebut hanya berlaku pada siswa-siswa yang cerdas, sedangkan siswa yang tidak terlalu pintar cenderung pasif dalam diskusinya, mereka merasa tidak bisa menjawab sama sekali. Hal itu dikarenakan para siswa tersebut tidak terbiasa menyelesaikan masalah yang nyata, mereka lebih terbiasa menyelesaikan masalah setelah ada contoh soal dari guru sehingga mereka kesulitan menangkap inti dari pembelajaran tersebut. Proses diskusi dan tanya jawab terjadi hanya antar siswa yang pintar, tidak semua siswa mengeti inti dan konsep dari pembelajaran yang diberikan (Saleh, 2013)

Pemahaman siswa yang diajarkan menggunakan Mind Mapping sebagai model pembelajaran lebih merata, dan kesenjangannya tidak terlihat antara siswa yang pintar maupun tidak, malah yang terlihat hampir sebagian besar siswa memahami konsep dengan mudah. Peta konsep yang disediakan peneliti adalah stimulus yang mudah diterima dan di respon oleh siswa. Hal tersebut dilihat dari mudahnya siswa menjawab pertanyaan yang diberikan oleh peneliti dan mengingat ide-ide apa saja jika ditanya ulang, siswa dapat dengan dengan mudah dan terstruktur mengetahui inti dari sebuah materi pelajaran dari peneliti.

Mind mapping merupakan suatu teknik dalam mencatatan suatu gagasan atau ide-ide pikiran yang dapat digunakan untuk mempermudah pemahaman dalam suatu pembelajaran yang dicatat dengan menggunakan teknik memetakan pikiranpikiran yaitu menggunakan peta, gambar, 
dan simbol secara kreatif dan efektif yang biasanya digambar secara kesatuan (Zulfia Latifah dkk, 2020). Kreativitas dalam pembelajaran ini tentu penting karena dapat melatih kelacaran mengemukakan ide dan keluwesan dalam mengajukan pemecahan masalah dengan cara yang berbeda, dalam keaslian menghasilkan ide tersebut didasarkan dari pemikiran sendiri dengan menguraikan ide secara rinci (Yuniharto \& Susanti, 2019). Selain itu juga siswa terlatih kreatitivitasnya dalam menghasilkan gagasan serta gambaran objek dengan cara-cara yang baru dan melatih siswa dalam pemecahan masalah, selain itu ide-ide atau gagasan yang unik dapat dengan mudah dihasilkan oleh siswa (Pamungkas et al., 2017)

Setelah peneliti memberikan
perlakuan menggunakan mode
pembelajaran Mind Mapping menunjukkan pula lebih banyak siswa catatannya tertulis dengan rapi. Pencatatan tersebut tentu akan berguna pada saat belajar mempersiapkan latihan soal, kuis, ujian ataupun post test yang akan diberikan oleh guru sehingga siswa tidak akan lupa akan pembelajaran yang telah dipelajari sebelumnya karena sudah tercatat dengan rapi pembelajaran lebih efektif dan efisien. Model pembelajaran mind mapping ini dirancang agar siswa dapat mengembangkan ide pokok dari konsep menjadi peta pikiran agar siswa lekas sekali mengerti terhadap apa yang disusun dengan kreatif (Darusman, 2014). Sehingga secara klasikal dikatakanlah Mind Mapping yang diterapkan sebagai model pembelajaran kooperatif lebih cocok untuk siswa kelas X SMA Negeri 3 Singaraja pada mata pelajaran ekonomi. Hal tersebut sejalan dengan teori bahwa "Mind Mapping cocok bagi semua mata pelajaran termasuk diantaranya pelajaran ekonomi, karena pelajaran ekonomi adalah satu dari banyak pelajaran yang materinya memang banyak yang perlu dihafal, dengan demikian Mind Map dapat dengan mudah menyederhanakan materi tersebut, sekaligus membuat belajar lebih menyenangkan" (Windura, 2016).

Penelitian dengan tajuk "Penerapan Model Pembelajaran Mind Mapping Terhadap Hail Belajar Pada Mata Pelajaran
Ekonomi di SMA" oleh (Putri dkk, 2015) yang dilakukan di SMA Islam BAWARI Pontianak juga memberikan dukungan atas hasil penelitian ini. Hasil analisis data yang ditunjukkan yakni adanya perbedaan positif serta signifikan hasil belajar pelajaran ekonomi di kelas eksperimen yang lebih baik jika dibanding dengan nilai kelas kontrol kelas X. Penelitian lainnya, bertajuk "Pengaruh Model Pembelajaran Mind Map Terhadap Hasil Belajar Siswa Pada Materi Sistem Ekskresi di Kelas XI IPA SMA Swasta Prayatna Medan" oleh (Saragih \& Manurung, 2018), menghasilkan pernyataan bahwa pada tahun pelajaran 2015/2016, di SMA Prayatna XI IPA 2 memperlihatkan perbedaan positif serta signifikan hasil belajar pelajaran biologi di kelas eksperimen yang lebih baik jika dibanding dengan nilai kelas kontrol.

\section{SIMPULAN DAN SARAN}

\section{Simpulan}

Ajuan yang didasari oleh rumusan masalah dan hipotesis penelitian, maka peneliti dapat menarik kesimpulan yaitu adanya perbedaan positif serta signifikan hasil belajar pelajaran ekonomi antara kedua kelas. Pada kelas eksperimen yang memakai Mind Mapping sebagai model dalam pembelajaran, peneliti memakai $X$ IPS 1 pada riset ini. Sedangkan, pada kelas kontrol yang memakai Problem Based Learning sebagai model dalam pembelajaran, peneliti memakai X IPS 3 pada riset ini. Agar dapat mendukung riset ini, nilai signifikansi harus $<0,005$. Berdasarkan ringkasan Independent Sample $t$-Test yang telah tersaji pada Tabel 1, pada kolom Sig. (2-tailed) terdapat nilai 0,000 pada kedua baris yang tersaji, 0,000 $<0,005$ atau nilai signifikansi $<0,005$ hal tersebut mengindikasikan $\mathrm{H}_{0}$ dapat diterima.

\section{Saran}

Berdasarkan hasil pembahasan, dan juga simpulan yang sebelumnya telah diuraikan, saran yang diperuntukkan oleh guru ekonomi dari peneliti, agar mengaplikasikan kooperatif tipe Mind Mapping sebagai satu pilihan diantara sekian banyak model untuk diterapkan di kelas untuk menaikkan hasil belajar siswa 
kelas X SMA Negeri 3 Singaraja pada saat pembelajaran berlangsung. Saran bagi peneliti selanjutnya, untuk lebih membentangkan penelitian tentang model pembelajaran Mind Mapping dengan pokok pembahasan yang berbeda, karena di dalam penelitian ini hanya meneliti terkait hasil belajar saja, karena keberhasilan pembelajaran tidak hanya diukur dari satu variabel sehingga untuk peneliti selanjutnya dapat menambah objek penelitian misalnya dengan membandingkan model pembelajaran Mind Mapping dengan kreatifitas siswa atau yang lain sebagainya.

\section{DAFTAR PUSTAKA}

Aunurrahman. (2012). Belajar dan Pembelajaran. Bandung: Alfabeta CV.

Darusman, R. (2014). Penerapan Metode Mind Mapping (Peta Pikiran) Untuk Meningkatkan Kemampuan Berpikir Kreatif Matematik Siswa SMP. Infinity Journal, 3(2), 164.

Fauziah, D. N. (2017). Penerapan Model Mind Map Untuk Meningkatkan Kreativitas Dan Pemahaman Siswa Pada Materi Sejarah Kerajaan Islam Di Indonesia. Mimbar Sekolah Dasar, 4(2), 128-138.

Hermaswari, M. S., Meitriana, M. A., \& Tripalupi, L. E. (2019). Pengaruh Model Pembelajaran Attention, Relevance, Confidence, and Satisfaction (ARCS) Terhadap Aktivitas Dan Hasil Belajar Ips Terpadu Di Smp N 2 Sawan. Jurnal Pendidikan Ekonomi Undiksha, 10(1), 136.

Nurdyansyah, \& Fahyuni, E. F. (2016). Inovasi Pembelajaran Sesuai Kurikulum 2013. Nizamia Learning Center.

Pamungkas, A., Subali, B., \& Linuwih, S. (2017). Implementasi model pembelajaran IPA berbasis kearifan lokal untuk meningkatkan kreativitas dan hasil belajar siswa. Jurnal Inovasi Pendidikan IPA, 3(2), 118.

Prahara, R., Wahyono, H., \& Utomo, S. (2016). Kualitas Pembelajaran Ekonomi Di Sman Dan Man Malang Raya. Jurnal Pendidikan - Teori, Penelitian, Dan Pengembangan,
1(12), 2266-2271.

Putri, Zuyyina Hasdillah; Ulfah, Maria; Rosyid, R. (2015). Penerapan Model Pembelajaran Mind Mapping Terhadap Hasil Belajar Pada Mata Pelajaran Ekonomi di SMA. 4. No. 11.

Saleh, M. (2013). Strategi Pembelajaran Fiqh Dengan Problem-Based Learning. Jurnal IImiah Didaktika, 14(1), 190-220.

Saragih, D. S., \& Manurung, N. (2018). Pengaruh Model Mind Map Terhadap Hasil Belajar Siswa Pada Materi Sistem Ekskresi di Kelas XI IPA SMA Swasta Prayatna Medan. Best Journal (Biology Education, Sains and Technology), 1(1), 21-28.

Syam, N., \& Ramlah, R. (2015). Penerapan Model Pembelajaran Mind Mapping Dalam Meningkatkan Hasil Belajar Pada Mata Pelajaran IImu Pengetahuan Sosial Siswa Kelas Iv Sdn 54 Kota Parepare. Publikasi Pendidikan, 5(3).

Tayeb, T. (2017). Analisis dan Manfaat Model Pembelajaran. Jurnal Pendidikan Dasar Islam, 4(02), 48-55.

Windura, S. (2016). Mind Map Langkah demi Langkah. Elex Media Komputindo.

Yuniharto, B. ., \& Susanti, M. M. . (2019). Peningkatan Minat Belajar dan Kreativitas Siswa Kelas IIIA SDN Maguwoharjo 1 Melalui Model Pembelajaran Kooperatif Tipe GI Pada Materi Pertumbuhan dan Perkembangan Tumbuhan. Elementary Journal Vol, 1(2), 22-32.

Zulfia Latifah, A., Hidayat, H., Mulyani, H., Siti Fatimah, A., \& Sholihat, A. (2020). Penerapan Metode Mind Mapping Untuk Meningkatkan Kreativitas Pada Pembelajaran Pendidikan Kewarganegaraan. Jurnal Pendidikan, 21(1), 38-50. 